\title{
An Efficient Electrocatalyst based on Platinum Incorporated into N,S co-doped Porous Graphene for Oxygen Reduction Reaction in Microbial Fuel Cell
}

\author{
S. Sadegh Hassani ${ }^{1}$, M.R. Ganjali ${ }^{1,2, *}$, L. Samiee $^{3}$ and A.M. Rashidi ${ }^{4}$ \\ ${ }^{1}$ Center of Excellence in Electrochemistry, School of Chemistry, College of Science, University of \\ Tehran, Tehran, Iran \\ ${ }^{2}$ Biosensor Research Center, Endocrinology and Metabolism Molecular-Cellular Sciences Institute, \\ Tehran University of Medical Sciences, Tehran, Iran \\ ${ }^{3}$ Energy Technology Research Division, Research Institute of Petroleum Industry (RIPI), West Blvd. \\ Azadi Sport Complex, P.O. Box 14665-137, Tehran, Iran \\ ${ }^{4}$ Nanotechnology Research Center, Research Institute of Petroleum Industry (RIPI), West Blvd. Azadi \\ Sport Complex, P.O. Box 14665-137, Tehran, Iran \\ *E-mail: ganjali@khayam.ut.ac.ir
}

doi: $10.20964 / 2018.11 .77$

Received: 10 August 2018 / Accepted: 21 September 2018 / Published: 1 October 2018

In this work, an efficient electrocatalyst nanomaterial for application in fuel cells was introduced. The nanomaterial was prepared through platinum incorporation into the S,N co-doped porous graphene (PG) through pyrolysis method. The physico-chemical properties of the prepared samples were characterized using X-ray Diffraction (XRD), Raman spectroscopy, $\mathrm{N}_{2}$ sorption-desorption, Transmission Electron Microscopy (TENM), Field Emission Scanning Electron Microscopy (FESEM) and X-ray Photoelectron Spectroscopy (XPS). The synthesized samples were further applied for oxygen reduction reaction (ORR) and evaluation in microbial fuel cell (MFC). The results revealed that impregnation of $10 \mathrm{wt} . \% \mathrm{Pt}$ into the nitrogen and sulfur co-doped graphene structure (called GSTP-900-Pt 10) cause more improvement in catalytic activity compared to $20 \mathrm{wt}$.\% Pt/C. Also, LSV measurements confirmed an improved onset potential $(1.00 \mathrm{~V})$ for G-STP-900-Pt 10 sample in comparison with $20 \mathrm{wt} . \% \mathrm{Pt} / \mathrm{C}(0.99 \mathrm{~V}$ vs. RHE). Furthermore, microbial fuel cell test showed higher cell potential and power density relative to $\mathrm{Pt} / \mathrm{C} 20 \mathrm{wt} \%$ too. Finally, for economic purpose, the optimal sample with lower Pt amount (10 wt.\% Pt) was selected as a good candidate for ORR in MFCs.

Keywords: Oxygen reduction reaction, Microbial fuel cell, Porous graphene, Platinum, Nitrogen and sulfur co-doped graphene. 


\section{FULL TEXT}

(C) 2018 The Authors. Published by ESG (www.electrochemsci.org). This article is an open access article distributed under the terms and conditions of the Creative Commons Attribution license (http://creativecommons.org/licenses/by/4.0/). 